\title{
Éloge de la Méthode: A Tribute to Garrison Sposito on the Occasion of His Retirement
}

\author{
Laurent Charlet $^{1 *}$, John Baham ${ }^{2}$, Juan V. Giraldez ${ }^{3}$, WeiCheng Lo ${ }^{4}$, Ludmilla Aristilde ${ }^{5}$ and \\ Philippe C. Baveye ${ }^{6}$
}

${ }^{1}$ Institut des Sciences de la Terre (ISTerre), University of Grenoble and Centre National de la Recherche Scientifique, Grenoble, France, ${ }^{2}$ Department of Crop and Soil Science, Oregon State University, Corvallis, OR, USA, ${ }^{3}$ Department of Agronomy, Universidad de Cordoba, Cordoba, Spain, ${ }^{4}$ Department of Hydraulic and Ocean Engineering, National Cheng Kung University, Tainan, Taiwan, ${ }^{5}$ Department of Biological and Environmental Engineering, College of Agriculture and Life Sciences, Cornell University, Ithaca, NY, USA, ${ }^{6}$ UMR EcoSys, AgroParisTech, Université Paris-Saclay, Thiverval-Grignon, France

OPEN ACCESS

Edited by:

Denis Angers,

Agriculture and Agriculture-Food

Canada, Canada

Reviewed by:

Zhili He,

University of Oklahoma, USA

Christina Bogner,

University of Bayreuth, Germany

*Correspondence:

Laurent Charlet

charlet38@gmail.com

Specialty section:

This article was submitted to

Soil Processes,

a section of the journal

Frontiers in Environmental Science

Received: 24 August 2016

Accepted: 28 October 2016

Published: 10 November 2016

Citation:

Charlet L, Baham J, Giraldez JV,

Lo W, Aristilde $L$ and Baveye PC (2016) Éloge de la Méthode: A Tribute

to Garrison Sposito on the Occasion

of His Retirement.

Front. Environ. Sci. 4:73.

doi: 10.3389/fenvs.2016.00073
When confronted with a great piece of art or research, one often wonders about what made it possible, what method was used by its author, in part so one can try to emulate it in one's own activities. Upon the retirement of Garrison Sposito after a long and very distinguished career, we considered that, as former doctoral students of Gary's, we were in a privileged position to write, in our own words and from our perspective, an account of the various key ingredients of his very successful "method." In the following, we identify and review six components of this method, respectively his thorough bibliographical coverage, extreme rigor in research, meticulous crafting of manuscripts, parallel focus on several disciplines, firm conviction that it is not necessary to go out of one's way to promote good ideas or competent people, and finally his reluctance to jump on bandwagons. We hope that this analysis of the pillars of Gary's method, at least as we see them, will not only help pay tribute to an outstanding thinker, but also inspire and provide a roadmap to all those who strive to better themselves as researchers.

\section{Keywords: scientific research, scientific method, epistemology, publishing, mentoring}

\section{INTRODUCTION}

When one encounters a masterpiece, be it a poem, a sculpture, a painting, a remarkable architectural design, or an extremely moving piece of music, the most common reaction at first is to be thoroughly awestricken. Soon thereafter, consciously or unconsciously, we often tend to wonder what made such a marvel possible. We recognize implicitly that genius must have been involved in the creation of the work of art in front of us, and therefore that there is no real hope for most of us to fully grasp how it came about, or even simply to imitate what the artist has done. And yet, we would still like to get a feel for at least some of the ingredients involved, so that we could try to emulate them, modestly, in our own creative efforts.

The same goes, to a large extent, when contemplating the scholarly production of a great researcher. In recent years, careers have been increasingly gauged with all kinds of statistics, like the total number of articles or citations, the h-index a person has achieved, or the awards s/he has received. None of these numbers, however, provides any assurance that a potential recruit will ever become a fantastic researcher, or explains in what manner the work that was carried out by an 
established scientist has inspired awe in those who studied it. These statistics definitely provide no answer whatsoever to the questions that each of us tends to ask eventually, concerning what made it all possible.

Many factors undoubtedly contribute to boost the creativity of a researcher, like a particularly stimulating family environment in which the person grew up, inspirational mentors in the formative stages of the person's career, and, as the case may be, a very supportive and creative spouse/partner as well as understanding children (or vice-versa). Those are facets of a researcher's background that, for privacy reasons, s/he may not be very comfortable to share indiscriminately with a broad public. However, other features may be less private, related directly or indirectly to the method that the person has perfected over the years to carry out his/her research. In some instances, these features may offer useful clues as to the reason for the person's success.

In this general context, we thought that to start this special issue devoted to Garrison Sposito on the occasion of his official retirement after a long and exceptionally distinguished career, it might be useful for a few of his former doctoral students to describe what we see as the basic tenets of his method. These are not secrets to which somehow we would be privy and whose sharing might be considered an indiscretion. In fact, anyone patient enough to sieve through the hundreds of articles that Gary has published over several decades in fields as disparate as quantum physics, soil physics, hydrology, soil chemistry, and even geomicrobiology, would likely be able to come up with most of the same observations we make here. However, in our case, it takes us less time to put the pieces of the puzzle together, so to speak. Our work with Gary has indeed exposed us directly to his approach and philosophy. It also stimulated us to keep track, year after year, of at least a portion of what he and his collaborators were publishing, so that we now have perhaps a slightly better vantage point than most from which to produce a synthetic picture. Occasionally, there may be in what follows some observations or comments that it would be hard to glean from the literature, but they refer to aspects of Gary's method that are commonly known among the many people who have collaborated with him, or among reviewers of his manuscripts.

From our perspective, Gary's method encompasses six main components. They deal respectively with his thorough coverage of the relevant bibliography, rigor in addressing research questions, extreme attention to the crafting of manuscripts, consistent efforts to keep irons simultaneously in several disciplinary fires, a notion that neither ideas nor people need to be overly promoted if they are sound, and finally a clear tendency not to jump on bandwagons. Each of these themes is discussed in turn in the following. This sequential presentation forces us to discuss the key themes separately and to order them in some fashion, both of which are artificial since these themes are clearly interconnected. Nevertheless, we hope that this analysis will not only serve as a tribute to Gary's amazingly productive career, and complement in this respect other tributes that have been written in the past (e.g., Chorover et al., 2007), but also will be of use to scientists all over the world who are searching for the most effective ways to proceed in their own work. In a broader sense, we are also hoping that our emphasis on intangible aspects of Gary's career, which are not easily encapsulated in any kind of metric, will in the future stimulate readers to be creative, rather than formulaic, when evaluating the impact of fellow researchers.

\section{EXHAUSTIVE COVERAGE OF THE LITERATURE}

Probably the aspect of Gary's method that is the most noticeable upon even a cursory survey of some of his articles, is how consistently comprehensive his coverage of the literature is. One would be hard pressed to find a single article of his where a significant previous work has not been thoroughly analyzed and cited, no matter how long ago or in what language this earlier research was published, and whether it was in a widely available or relatively inaccessible publication. It is obvious that, in this respect, a basic foundation of Gary's philosophy is that sound research imperatively rests on an extensive knowledge of the relevant work done in earlier times by everyone who contributed even an iota to the advancement of knowledge in the field. This attitude is in keeping with the age-old saying Gary likes to repeat and according to which, in everything that we do in research, we stand on the shoulders of some of the giants who have preceded us.

One could remark that in this day and age it is easy for Gary, like anyone else, to do bibliographical searches with the various indexes (e.g., Web of Knowledge, Scopus, Google Scholar) at his disposal, and also given the extraordinary richness of undoubtedly one of the best academic libraries in the world, accessible to Gary on the Berkeley campus. However, the meticulous attention to anterior literature, which characterizes Gary's latest articles, is already evinced in work he carried out in the 1960s and 1970s, when he was a faculty member in physics at Rhonert Park and later in soil science at Riverside. Indexing was extremely limited back then, and Gary did not yet have access to library facilities of Berkeley's caliber. To leave no stone unturned in terms of the relevant literature, Gary had to (and did, systematically) spend many hours searching with great obstinacy through dusty library stacks, and send a multitude of reprint request cards to all corners of the world.

As we all know, finding the right primary sources is only part of the battle. To do a thorough job covering the literature, one still needs to read these documents in depth. Experience shows that very few researchers either have the personal discipline or manage to find the time to do this to the same extent that Gary always has. In this respect, there is little doubt that a key to Gary's ability to spend substantial time reading the literature is that he has consistently kept the number of his graduate students down to a manageable number (rarely more than 4), and systematically refused to let anyone try to "promote" him to long-term administrative positions, as a department chair or higher up, except for a very short stint as acting department chair at Berkeley. As a matter of fact, when so many of his peers were becoming overloaded with personnel management issues in their large research team, department, or college, Gary remained a researcher, able among other things to keep reading the literature 
first-hand and to devote a considerable portion of his time simply to thinking.

In pre-personal-computer days, many of Gary's visitors, after being astonished by the exiguity of his office (especially of his tiny monastic cell in Riverside), would ask some of his graduate students where Gary kept his "documentation." The presumption was that someone who demonstrated such an encyclopedic knowledge of the literature as he did must have had rooms full of file cabinets overflowing with reprints and photocopies of articles available at his fingertips. The fact is that Gary kept extremely few articles. Soon after the publication of a manuscript, he would tend to discard all the documentation he had assembled for it. If, at a later time, he wanted to write another manuscript on the same subject, his approach was to revisit the past literature as if he were starting from scratch. This trick may be a little surprising, and one might consider it a waste of valuable time, yet it prevents one from becoming complacent about bibliographical research and it forces one to repeatedly take a fresh look at all relevant sources. By starting anew each time, and following every possible lead methodically and relentlessly, one is almost guaranteed to do an exhaustive job in the end, as amply demonstrated by Gary's scholarly output.

Gary's care to unearth all possible relevant bibliographical sources, and to analyze them in great detail, is probably nowhere clearer than in the various seminal review articles and books that he has written over the years. Time and again, his all-encompassing grasp of the literature has allowed him to understand concepts and processes at a far deeper level than was the case before him. A very good example in this respect is a landmark article he co-authored with René Prost in the early 1980s (a publication that, anecdotically, was made particularly memorable to Gary by the fact that parts of it were written without any access to a library, in the middle of an absolutely deserted research center, in Versailles, during the sacrosanct Summer holiday in August). Whereas previous researchers had for years bickered about "the" "correct" structure of water adsorbed on smectites, Sposito and Prost (1982) demonstrated as part of a comprehensive review of the literature that the various spectroscopic instruments in use were probing water at widely different time scales, and that the different structures that had been proposed in the literature were therefore not contradictory, but merely represented distinct snapshots of the same, complex reality. Sposito and Prost's (1982) systematic analysis also showed decisively that when relevant data were handled properly, the then-often-promoted notion of ice-like water structure extending many molecular distances away from smectite surfaces lacked any experimental support.

On a very different topic, the frequently cited review article of Sutton and Sposito (2005), dealing with the molecular structure of humic substances, proposed a unique and remarkably crafted synthesis of the related literature, and contributed very significantly to the sea change that has occurred since 2005 in the study of soil organic matter. In the beautifully-written introduction of a subsequent article they wrote (Sutton and Sposito, 2006), not only did they argue for the need to use Molecular Dynamics to understand the storage of carbon in soils at the landscape scale, by drawing on and connecting literature sources from very different horizons, but they managed to do so extremely convincingly, an impressive feat not very many people could have achieved.

In his supervision of graduate students and postdocs, not surprisingly, Gary has consistently emphasized from the onset the need to read the literature exhaustively, which he often refers to as one of the two key avenues toward success, the other being self-discipline. Whether students will achieve success after engaging along these two avenues, according to Gary, depends on three criteria, which he occasionally writes down on a small yellow sheet of paper the students find on their desk on their first day. These three criteria are "honesty," "patience," and "willingness to fail." The second of these criteria is especially significant when it comes to reading the literature, but also when experiments do not produce the results that the students expect.

\section{RIGOR IN ADDRESSING RESEARCH QUESTIONS}

Besides the fact that, as a rule, they are based on an exceptionally thorough coverage of the literature, articles written by Gary also stand out by virtue of their extreme rigor. This rigor manifests itself in a number of respects. In most areas in which he has published, Gary's articles stand out not only because of the painstaking attention he pays to clearly state the research objectives he pursues, but also because these objectives are never related to the use of a particular conceptual tool or piece of equipment. With remarkable consistency, Gary's articles are never method-driven, but instead always address well-defined conceptual questions. This is the case even in articles of his that deal with interfacial and microbiological issues, in spite of the clear tendency of research in spectroscopy and microbiology to be more led by specific methodologies than in other fields.

A second area where his rigor manifests itself is in the precise definition of terms or concepts used in the research. In a number of cases, his need for rigor led him to address the confusion associated with the use of conflicting terminologies in the literature, and to propose instead a sound, theoreticallybased terminology, to which he adhered thereafter, without fail. A salient example is the article he wrote on the definitions of various points of zero charge in soils (Sposito, 1981). Gary likes to point out that this article was first summarily rejected by reviewers, before becoming a standard reference.

In theoretical developments, in situations where many other researchers appear willing to take shortcuts or introduce assumptions that are heuristically motivated, Gary has systematically held very strict standards. An example concerns the explicit account of air-water interfaces in the development of thermodynamic theories of porous media. In his book on the thermodynamics of soil solutions (Sposito, 1981), adhering to opinions expressed earlier by continuum mechanicists, he argued that since thermodynamics is by definition a macroscopic theory, a thermodynamic description of equilibrium states in soils should only involve strictly macroscopic parameters. Therefore, non-macroscopic features, like the shape or position of air-water interfaces, or for that matter, any molecular-scale 
aspect of soils, are perforce irrelevant. Gary never waivered from this perspective in later articles. Another example is related to fractals. When, in 1989, Michel Rieu (on sabbatical from France) and Gary started working on the application of fractal geometry to soils, they rapidly identified as a fundamental lack of rigor the assignment by other scientists of fractal dimensions that were larger than that $(=3)$ of the Euclidean space in which soils exist physically. The seminal research they published together (Rieu and Sposito, 1991a,b,c; Perrier et al., 1996) rigorously constrained fractal dimensions, as they should be, to the dimensions of embedding spaces.

A final manifestation of Gary's meticulousness is related to the interpretation of experimental data. When working on articles describing the outcome of laboratory experiments or fieldwork, he consistently checks out himself all the calculations that his students or postdocs carry out, and he goes to great lengths to envisage and systematically test every conceivable explanation to account for observed results. A good example relates to the once puzzling observation of variable cation exchange capacities of smectite clays during binary cation exchange processes. Instead of accepting commonly advanced explanations, Gary and his co-workers came up with an elaborate alternative, involving ion pairing in chloride electrolyte backgrounds, and they proceeded to demonstrate the validity of this viewpoint by running experiments in perchlorate solutions (Sposito et al., 1983).

To some extent, perhaps more than the availability of funding for specific projects, we feel that this need to uphold extremely high standards of rigor in his articles has influenced the topics that Gary has addressed over the years, and especially the choice of scholarly journals where he has published his work. Whereas much of his research in the 1970s and 1980s ended up getting published in soil science journals, it is clear that, since, his scholarly output has migrated increasingly to geochemistry, environmental science, and to some extent, water resources related journals.

\section{EXTREME ATTENTION TO THE CRAFTING OF MANUSCRIPTS}

Those of us who have edited journals are unfortunately familiar with graduate students or postdocs submitting half-baked manuscripts that the-otherwise respectable-researchers who supervise them have not spent much time editing or may not even have read, although they are listed as co-authors. The implicit assumption underlying this practice of "prima donnas" is that reviewers and editors of the journals will take care of polishing the manuscripts into something publishable. If there is a "conviviality" spectrum at the low extreme of which these individuals reside, then Gary is resolutely at the extreme opposite. He always takes great care to ensure that anything bearing his name, and especially the work of his graduate students, is in as near to perfect a shape as possible when it is submitted for publication. He usually argues that this is a good strategy, because it tends to make the review process much more straightforward than it would otherwise be, but there is also, undoubtedly, a component in his approach that is motivated by utter respect for the time and work of his peers, who eventually have to review the work. At a time when the number of submitted manuscripts increases exponentially while the number of competent peer reviewers tends to stay relatively constant, most journal editors would undoubtedly appreciate it immensely if more authors had a similarly high sense of ethics and collegiality.

To produce manuscripts that are in great shape, prior to submission, Gary has traditionally adopted an approach that is different than that of most other scientists, at least of those with whom we have been in contact. When receiving a manuscript from a graduate student, many professors (at least those who spend much time on their students' manuscripts) proceed by iteration, pointing out aspects of the writing that need further work, and sending the manuscript back to the student for revision, until eventually, after sometimes months of going back and forth, the manuscript is deemed ready for submittal. Gary's modus operandi is radically different. After having discussed in detail with his graduate students the work that they have done, encouraging them to alternatively put on an author- and a reviewer hat to look at the text, and after checking himself that whatever calculations they have carried out are correct, Gary asks the students to give their best shot at writing, in their own words, a text that describes their work. From this document, in a very short time, sometimes as brief as a weekend, he produces a document that, for all practical purposes, is complete and ready to be submitted.

In the pre-computer days, these finished products came in the form of a stack of yellow legal-format sheets, on which Gary had hand-printed the new text, with occasional, heavily-edited cutouts of the original text of the student pasted in, as in Figure 1. Gary's text would generally be striking in its neatness, and by the fact that it seemed to have been produced in one continuous stream, requiring very few later changes. In addition to the text itself, Gary used to give very precise information to the typist on the formatting of the final document. The same applied to the manuscripts of his many books, which consisted of a pile of yellow sheets that we saw growing steadily over time in a corner of his office, until a day when the writing was completed, the book ready, and the pile sent to the typist, on its way eventually to the publisher. In the computer era, of course, the stacks of yellow sheets are no longer necessary, and Gary's editing occurs slightly differently. Nevertheless, when he does not rewrite the entire text outright, he provides extensive hand-written notes on a hard copy of the manuscript, with copious suggestions of where to move large portions of texts around.

In the case of students' articles, in the pre-computer days, the new version of the manuscript, in most instances, bore very little resemblance in terms of both flow of ideas and format, to the original text given by the student to Gary. There was a risk under these conditions that some students would feel that the final product was not their work anymore, in other words, that they had lost "ownership" over it. However, most students working with Gary, setting their pride aside, realized quickly that by comparing their own text side-by-side with what Gary had made of it, they had a unique opportunity to learn quickly, from a master craftsman, what putting a manuscript in good shape for 


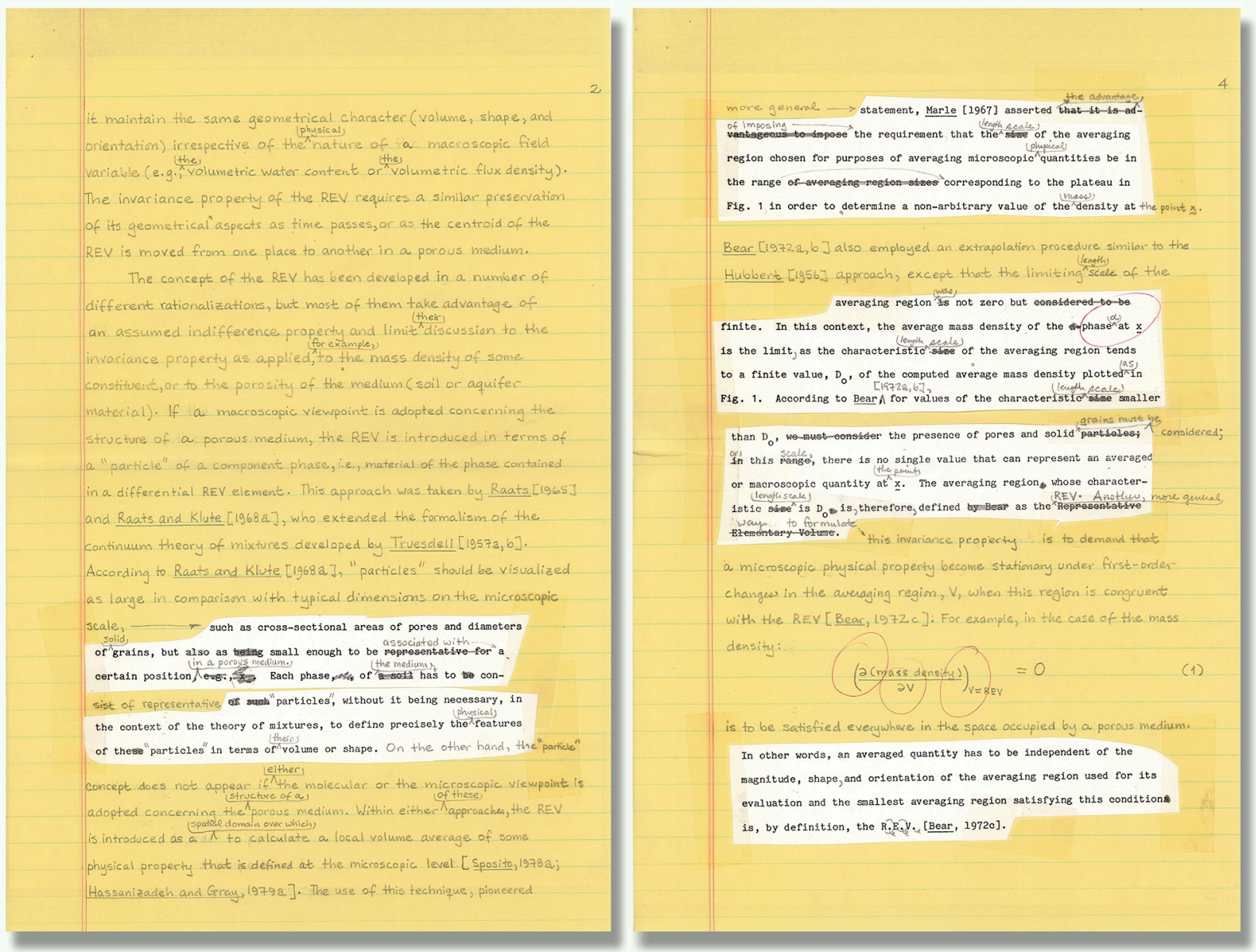

FIGURE 1 | Example of the pages of a pre-personal-computer-era manuscript that was rewritten by Garrison Sposito based on a graduate student's original text. Gary's hand-printed script on yellow sheets typically proposes a very fluid story, in which heavily edited sections of the graduate student's original text (on white paper) are pasted where they fit logically.

publication really encompasses. That does not mean that it was easy for any of us, later on, to emulate his example when the time came to produce our own articles, but we all feel that we learned more about scientific writing from being exposed firsthand to his example than we would if we had iterated for months on our manuscripts, had felt dejected at each step of the process, and in the end had been too sickened by the whole operation to really appreciate how much the manuscript had evolved since the beginning of the iterative process.

A possible downside of Gary's "single-shot" approach to working on his students' manuscripts is that it requires a tremendous concentration, and a degree of isolation, to be able to write an attractive and rigorous story from A to $\mathrm{Z}$. The iterative approach, by comparison, requires far less concentration, or at least allows thesis advisors to divide in discrete chunks the time they devote to a manuscript, during which they edit a few pages, before moving on to deliver a lecture, attend a meeting, or catch a plane. In these cases, interruptions are not ideal, but they do not necessarily hinder the commenting process. By contrast, to conceive and write a whole story, little chunks of time are not acceptable, and neither are frequent disturbances or interruptions. For at least part of his workdays, Gary has resolved the associated need for seclusion in a somewhat unique manner. Typically, in the morning, he begins the writing process in his head during the commute to campus, where he typically arrives very early, way before anyone else. He then has about 2-3 h of quality, totally uninterrupted writing time, before others get in.

Various aspects of Gary's attention to details in the crafting of manuscripts are easy to notice upon reading even just one of his manuscripts. Aside from the existence of a clear story line in each of his manuscripts, a hallmark of his style is that he does not subscribe to the notion that good scientific writing necessarily calls for short sentences and a generic, simple vocabulary. Bucking the general trend, Gary is never been afraid to use relatively sophisticated words and complex sentence structures, whenever he feels that they are necessary to convey accurately 
his viewpoint on complicated ideas. In this respect, he often mentions that when he was a teenager, he had aspirations of becoming a fiction writer. His virtuosic command of the English language definitely suggests that he had the potential to be a great one, indeed. Another hallmark of Gary's writing style is found at the beginning of his article, in the introduction, which typically grips readers' attention from the first sentence onward and eventually leaves them utterly convinced that the subsequent text not only addresses an issue of enormous importance, but justifies putting everything else aside to keep reading the amazing story that follows.

An anecdote, shared by Gary with one of us (JVG), illustrates the power of his attention to the story line in his writing. In the early seventies, Gary sent the last, typewritten draft of his book "An introduction to Classical Dynamics" from California to the New York office of John Wiley. Between California and New York, the mail got lost. It was, of course, a hard copy and, it turns out, the only existing copy of the manuscript (this was way before the advent of personal computers and of safe computing practices...). Gary did not complain, or get discouraged, and started to write the book again, from the beginning. In all likelihood, Gary had the whole story of the book, down to the slightest detail, still vividly in his mind, and this made tractable to him what to most other people would have been a horrendous ordeal.

\section{IRONS IN DIFFERENT DISCIPLINARY FIRES}

A question anyone who has worked with Gary is asked frequently by people who do not know him well, is whether Gary feels more like a physicist, a chemist, a physical-chemist, a mineralogist, or a geochemist, to name only a few of the hats that people think might be suitable for him to wear. It keeps puzzling people that Gary, unlike most researchers, be so difficult to completely pigeon-hole in one discipline or another, and many have a hard time understanding how a single person can keep abreast and remain competent in such a wide range of disciplines. Yet, this is exactly what Gary has managed to do, consistently and very deliberately, over the last 5 decades. During much of the 1970 s and 1980s, his work clearly demonstrates that he viewed the separation of soil physics and soil chemistry as totally arbitrary, a perspective that in many ways was shared also by his Ph.D. advisor at Berkeley, Kenneth Babcock, who in some of his landmark publications (e.g., Babcock, 1963) dealt with the physics and chemistry of soils as different aspects of a single extended continuum. However, later on, Gary also ventured beyond soils to geochemistry and hydrology, and included a very significant microbiological component as well, with the research he did after the 1990s on siderophores and on the microbial genesis of a number of minerals (Maurice et al., 1996; Toner and Sposito, 2005; Duckworth et al., 2009; Spiro et al., 2010; Peña et al., 2011).

The large range of topics covered does not apply only to research. In teaching also, Gary has maintained a very wide perspective. For many years, in addition to courses on the physical-chemistry and chemistry of soils for which he wrote textbooks that have become standard references, Gary taught an introductory course in hydrology with many real-life examples taken from hydrologist friends from the Russian River valley. In the last few years, at Berkeley, with Pulitzer-Prize-winning poet Robert Hass, he has also taught an innovative freshman course that surveys current global environmental issues, introduces students to the basic intellectual tools of environmental science, investigates ways the human relationship to nature has been imagined in literary and philosophical traditions or has even been literally man-made as the concept of "wilderness" by Californian poets, and examines how the tools of literary analysis, scientific method, and imaginative thinking can clarify what is at stake in environmental issues and ecological citizenship. Incidentally, the plan is for Gary to keep teaching this very popular course for a few years after his retirement.

To some extent, it does not surprise us that Gary would find intellectual stimulation in questions related to many different disciplines, not just within the narrow confines of the one discipline in which he happened to do his doctoral research. $\mathrm{He}$ is definitely not unique in having a wide range of interests. But, whereas for pragmatic reason, most researchers eventually restrict their field of vision, Gary consciously chose not to do so. His philosophy, often discussed with his students, is that the types of systems he works on, and the questions that are asked about these systems, are so complex, in so many different respects, that it is foolish to expect that simple answers will be found if one adopts only one vantage point and a single angle of view.

A key reason why many researchers feel the need to specialize at the start of their career is out of concern about making enough of a mark in one discipline to get tenure, and eventually to get recognition from their peers. It is clear that when Gary re-entered the discipline of soil science in 1974, after his stint in physics at Rhonert Park, none of that seemed to be on his mind. He had no qualms about immediately pursuing interests in several subdisciplines of soil science at the same time, at the risk of not being recognized by other researchers in particular fields as being entirely "one of them." History has shown that this did not prevent Gary from eventually gaining the accolades he deserved.

\section{MINIMAL PROMOTION NEEDED}

The question of recognition by his peers is crucial as well in another respect, which sets Gary apart from many researchers in the disciplines in which he has been active. Whereas many consider it a supreme achievement, and an ideal way to promote themselves and their work, to publish articles in some of the journals with the highest impact factors, like Science, Nature, or the Proceedings of the National Academy of Sciences (PNAS), Gary's work has been almost entirely absent from the pages of these journals. Chronologically the 4th and 5th articles he coauthored, based on work in soil physics carried out in Arizona during his Master's degree and published by his thesis supervisor, came out in Science and Nature (Anderson and Sposito, 1963; Anderson et al., 1963), Much later, after giving a talk at a symposium at the NAS Beckman Center in Irvine, he found out that the symposium organizers has arranged for the proceedings 
to be published in PNAS, which resulted in his only publication in this journal (Sposito et al., 1999). Aside from these isolated and involuntary occurrences, however, publishing in the "top" journals has never been a preoccupation at all for him.

In part, we feel that this is because the requirement to bring out the sensational aspects of one's writing in order to get published in these journals runs fundamentally counter to Gary's rigor, and in particular to his utter caution never to claim more than strictly what the results show. Gary always stresses the need for articles to be readily accessible to a wide audience and therefore to be published in journals of repute that are indexed in some of the major databases. But beyond this, his perspective has been consistently that sound research, accurately recounted without undue hyperbole, stands on its own, and that there is no need to go out of one's way to promote it, especially through efforts to publish it in journals with the highest possible impact factor (IF). Our reading of Gary's viewpoint is that it is sound content that should attract readers to a given article, not some artificial (and unreliable) measure of impact associated with the journal in which the article is published. In this respect, Gary's attitude is similar to that of a number of other great scientists. For example, the aquatic chemist Werner Stumm, who also published little in Science and not at all in Nature or PNAS, had no qualms publishing a number of landmark articles in Croatica Chemica Acta-a journal ranked fourth-tier by the Web of Knowledge-, apparently without ever worrying about the impact or reputation of the journal.

Parenthetically, there is little doubt that, until recently, Gary and Werner Stumm held a minority view on publishing in highIF journals, the majority of researchers following the flow and avoiding any discussion of the issue. But the wind seems to have shifted of late. Two years ago, Gelman (2014) made an incendiary off-hand comment about "tabloid science journals such as PNAS [that] provide incentives for researchers to engage in hype so as to get their papers published." The context was the reporting of questionable statistics in a particular high-profile PNAS article but, since then, this comment has been echoed by numerous people in a heated debate that has gotten the worldwide community of behavioral psychologists up in arms (e.g., Sijtsma et al., 2016). Discussions became particularly heated after a group of researchers developed a statistical program called "Statcheck" to assess the soundness of multi-hypothesis significance testing (NHST) results in articles published in psychology journals. Application of this package to a sample of 250,000 NHST analyses published in eight major psychology journals from 1985 to 2013 reveals that half of these analyses end up with statistically unsound results, with some systematic bias apparent toward establishing significance (Nuijten et al., 2015). So far, the huge storm that has resulted has been contained within the discipline of behavioral psychology, because the current version of Statcheck can only handle articles in the American Psychological Association format, but it is clear already that the type of checking it carries out is being expanded to other fields in which the lack of reproducibility of scientific results is a growing problem (e.g., Weissgerber et al., 2016). With internetbased tools becoming more and more sophisticated every year, it is likely that massive analyses similar to those enabled by
Statcheck will become routine in the future, and that researchers will be required to make their primary data readily available to the scientific community. At that stage, hyperbole of any kind, even in articles published in the past, may become seriously frowned upon. Under these conditions, researchers who were always extremely careful in their analysis of data, and who consistently refrained from overblowing the significance of their work, will be very happy they did. In that context as well, Gary may eventually be seen as a forerunner.

Anyway, aside from refraining to engage in hype, Gary, throughout his career, has also never made particular efforts to toot his own horn at annual meetings or conferences. Besides the fact that this would be entirely out of character, there is a very practical reason behind his attitude. Beginning when he was a graduate student, whenever an invitation would be extended to him to give a talk at a conference, he would systematically ask his family whether they wished to visit the location of the meeting. If they said "no," Gary would turn down the invitation. Having his family with him did not make him less available to his students and collaborators, on the contrary, but it reduced drastically the time during which Gary could engage in the kind of "socializing" that generally takes place during these events. In this respect, anecdotically, his daughter Jennifer may have been the youngest person ever to attend a board meeting of a scholarly society, sitting on the lap of her father while still a toddler!

One of the aspects of Gary's approach to science that these days seems most baffling to those who do not know him very well is his refusal to be considered for several honors for which so many others would have been willing to sacrifice an arm and a leg. Over the years, Gary has been warmly and enthusiastically recommended by his colleagues or collaborators for a large number of awards, and he has gladly accepted several of them. $\mathrm{He}$ was for example named as a "Legend of Environmental Chemistry" by the American Chemical Society, and is a foreign member of the French Academy of Agriculture. However, it is lesser known that Gary also refused a number of prestigious awards. In several cases, such as when he was offered the Brindley Lecture Award of the CMS or, recently, when he was invited to the White House for a high-profile meeting, he declined because of his family not being able to make the trip with him at the time planned for the award. In other cases, his motivation was different. After he moved to Berkeley, Gary made it clear that he did not want to ever be nominated for membership of the National Academy of Sciences of America, for reasons similar to those of Richard Feynman, who resigned from the NAS in 1963. In a nutshell, Gary did not see the point of being part of an institution whose meetings, as an academician described to him later, involved a lot of time spent by members lobbying to keep "their enemies" out of the NAS.

Another key reason for Gary's lack of interest in some honors, we feel, is the fact that they would have caused his fellow scientists or the public at large to harbor expectations of Gary, for example to deliver keynote lectures at various institutions, to take public positions on topical issues, or to attend timeconsuming committee meetings in Washington, all of which would distract him from the meticulous attention he wants to devote to his research. Like publications in high-impact factor 
journals, membership in the NAS would also have attracted attention to his work for reasons not necessarily related to the quality of the work itself, an outcome that runs counter to Gary's most fundamentally held beliefs.

By and large, Gary's attitude with respect to his students is that, in this case as well, there is no need to go out of one's way to actively promote them. That does not mean that he does not pay special attention to helping students blossom and grow intellectually. This is particularly the case with female graduate students. Indeed, beginning in about 1981, Gary's research group, intentionally, has included $50 \%$ of women, a conscious choice he made after he noticed that men in the group often did not know how to relate to women except as either sister or "girlfriend," but not as a colleague. He saw bolstering the fraction of women in the group as a way to solve this problem "by immersion," as it were. As a charter member of the NRC Committee on Women in Science and Engineering in the early 1990s, he wrote a chapter on problems women face trying to make a career in academia, and he expressed the view that "most of the problems women face in academia reflect a culture that has insufficiently recognized the capabilities and contributions of women and their potential, a culture that has not kept pace with women's changing employment patterns and society's increasing need for women scientists' talent. These problems are a result of our tendency to imagine the ideal scientist as a man who can single-mindedly devote $80 \mathrm{~h}$ a week to science because he has no constraining familial obligations" (Sposito, 1992) Gary's 50\% rule has definitely made a tremendous difference in his group, and has allowed many young women to get a foot in the door, which they may not have gotten easily otherwise.

After graduation is when Gary's perspective on "promotion" of his graduate students or postdocs differs from that of many of his peers, who devote a lot of energy and efforts to fostering a clique of faithful followers. In contrast, Gary has never tried to position his collaborators in key professorial positions in other universities, on the editorial boards of journals, or in key commissions and offices in some of the relevant scholarly societies. Neither does Gary make a special effort to cite his former students' articles to boost their image. Without ever saying so in so many words, he clearly holds the view that since his students passed the multiple hurdles he subjected them to, and are therefore well equipped to face all manners of trials and tribulations, they are very likely to succeed at whatever they attempt, without there being any need for him to actively interfere with the natural course of things or even to be a mentor to them. Occasionally, some former associates find Gary's "you are on your own once you leave the nest" attitude somewhat unsupportive and hard, but the upshot is that there is never any question about the true merit of any of us when something good happens, like a promotion or election to some office.

Most of those who, in one capacity or another, were exposed to the Sposito method have invariably been influenced by it, and this experience has shaped their worldview, often in very profound ways. As a consequence, we have been told that his former students and associates all tend to manifest a "je ne sais quoi" in their approach to science that clearly identifies them as Gary's intellectual children. So, even though Gary decidedly abhors the idea of a clique and has done everything possible not to foster one, an informal "Sposito school," with very distinctive features, has nevertheless developed over the years.

\section{NO JUMPING ON BANDWAGONS}

A final aspect of Gary's method that we think worth pointing out concerns his clear reluctance to join the fray whenever a group of researchers has decided that a particular avenue of research is worth pursuing for a variety of reasons. Over the last 50 years, there have been many fads in the different disciplines in which Gary has been active, and the existence of such fads has been eloquently deplored as counter-productive by various researchers. Thomas (1992), in particular, registered "some objections to what I see as more a concern with style than with substance in environmental and soils research. The blame for this must be shared by the granting agencies and the editors and other reviewers of scientific journals who demand and generally obtain adherence to the prevailing fashion of science. Nevertheless, more blame attaches to us, the people who do the work, for succumbing without a fight to whatever is popular at the moment." Vatn and Bromley (1994), in a description that is so well crafted that it is worth repeating in extenso again and again, state that "The history of science warns us that the mere popularity of a particular epistemological program is not sufficient evidence of its truth content. Nor is popularity a sufficient guarantee that those in a shared pursuit will not lose sight of the larger issues at hand. Indeed, it could very well be that the considerable popularity of a particular research program serves, in a perverse way, to reduce the probability that its ultimate purpose will be kept firmly in view. The very popularity of the research program then becomes self-reinforcing and serves both to envelope an ever larger share of those who might otherwise follow different research programs, and to stifle dissent out of fear of being thought out of the very broad and encompassing 'mainstream.' Meanwhile, the research becomes ever more involuted, and it becomes easier to lose sight of why one began the journey in the first instance. If we may be permitted a nautical metaphor, a long series of technically perfect tacking maneuvers may very well deposit the fastidious crew at a destination quite devoid of virtue."

The least one can say about Gary is that, to quote Thomas (1992), he has never succumbed "to whatever is popular at the moment." Instead, he has stayed consistently clear of many of the bandwagons on which his colleagues happily jumped. We feel that this has been partly due to a belief that it is not a good idea for the scientific community to put all its eggs in a small number of baskets or to put oneself in a position where it becomes easy, as Vatn and Bromley (1994) put it, to "lose sight of why one began the journey in the first place." In some instances, we feel that Gary's clear reluctance to follow fads was also motivated by the fact that they were approached by their promoters in ways that did not meet Gary's standards of clarity and rigor.

In the 1980s, while most soil physicists around the world were trying frantically to find ways to use geostatistics and kriging in their work in order to remain part of a growing "in-crowd," Gary 
decided instead to emphasize unresolved fundamental questions, which he described in a provocatively-titled article on "The physics of soil water physics" (Sposito, 1986), and to approach the problems associated with the spatial heterogeneity of soils in a different way (Sposito, 1993). In the 1980s as well, Gary observed carefully as article after article delved into the analysis of the kinetics of chemical reactions in soils and geochemical systems. When he eventually decided to join the fray, with a fundamental textbook on the topic (Sposito, 1994), it was obviously with the intent to guide the whole subject into a far more rigorous and theoretically sound terrain than where it had been until then. A similar comment could be made about the popular but contentious topic of soil quality, from which Gary also stayed clear for many years, except for a punctual attempt to inject much needed conceptual clarity (Sposito and Zabel, 2003).

Another area in which Gary has never ventured concerns the use of biochar. Some researchers routinely tout it as "the" solution to global climate change, whereas others, doing very careful work, point out potential limitations (e.g., Sánchez-García et al., 2014). Over the last 15 years that the biochar movement has been going on, not a single one of Gary's many articles has dealt with the topic in detail. Since more than a 100 of his publications deal with humus or organic matter in one way or another, including a highly cited review on soil humic substances (Sutton and Sposito, 2005), one definitely cannot attribute the absence of research by Gary on biochar to a lack of interest in the fate of organic matter in soils and subsurface environments. Our impression (which we fully realize will be controversial, and not shared unanimously) is that, in this particular case, Gary's reluctance to engage with the topic has to do with the fact that the research on it has not yet reached a sufficient level of maturity to benefit from an analysis of the key questions at the level of intellectual rigor that is typical of Gary's work.

One could mention many other "hot" topics, potentially within his very wide sphere of interest, on which Gary opted consciously not to work. The fact that he has felt neither the need nor the inclination to jump on every fad that came along has enabled Gary instead to keep working steadily and making progress on a number of topics that he considers important, regardless of what anyone else may think. One example concerns the molecular-scale modeling of clay surfaces and of chemical reactions that take place in their vicinity. Since he worked on this topic for his Ph.D. dissertation at Berkeley in 1963-1965, Gary has made a series of fundamental advances in the area over the decades, with a suite of collaborators (e.g., Chang et al., 1997; Sutton and Sposito, 2006; Bourg et al., 2007; Newton and Sposito, 2015). He has also maintained a keen interest in theoretical questions related to soils and geochemical systems (e.g., Sposito, $1997,2001)$, and occasionally some of these theoretical questions have even taken him somewhat outside of science (e.g., Sposito, 1969).

\section{ENVOI}

This list of six "pillars" that we have identified in the method that Garrison Sposito has used in his research over the decades is unavoidably subjective. It corresponds to the opinion of a small number of the many graduate students that Gary has had over the years. Other graduate students might easily have come up with a different list, or might have emphasized some aspects far more than others. Nevertheless, for us, these six components of the "Sposito method" have had a very strong and lasting influence on our professional development. In this context, a key reason that motivated us to spend time analyzing, and writing a detailed account of, the components of Gary's method was, as people say in France, to "joindre l'utile à l'agréable" (literally, combine what is useful with what is pleasant). By writing down in detail the fruits of our reflection, we hoped that it could inspire others to emulate Gary's example, or at least analyze their own practice.

We realize that, in this day and age, there are limits to the extent to which Gary's example can be followed, at least in countries like the US or China, where researchers are under tremendous pressure to produce. Quite a few young researchers in the US, at the formative stage of their career, especially if they have not yet gotten tenure, have told us repeatedly, and more and more frequently in the last few years, that if they do not make the numbers (e.g., in terms of publications in "top" journals, targeted increase in h-index over a certain number of years, and amount of grant money brought in), there is no hope for them to eventually get tenure. In other countries, like Germany, the pressure to publish is more reasonable, but young researchers have an extremely hard time to secure permanent positions, and candidates for jobs have to show they are able to lead a successful research program, with enough depth and without spreading themselves too thinly. In these different contexts, hearing our perspective on the pillars of Gary's method tends to make young researchers more sad than uplifted, as they realize that several of these pillars are unfortunately beyond their reach under current circumstances. One tongue-in-cheek response to these young researchers is that they should not hesitate to move to countries where they would have a better chance of combining family life and work, and in the latter context, be able to focus more freely on the quality of their research. Probably a more workable solution is for these young researchers to bite the bullet for the 6 years it takes to secure a permanent position, and satisfy meanwhile the various requirements they are subjected to, after which nothing prevents them, over the next 3 or 4 decades that their careers will last, to change the name of the game, "à la Sposito," and do research in a way that not only is more humanly and intellectually satisfying, but also ultimately better serves the needs of society.

To be honest, some of us had a hard time with one or more of the components of Gary's method when we were graduate students. It would be disingenuous of us to give the impression that to an eager Ph.D. student, the extremely thorough and meticulous way Gary does everything is not unnerving at times, especially compared to the apparently far simpler experience of graduate students dealing with "absentee landlord" advisors. For a few years after we left the nest of the Sposito group, some of us were determined to do things very differently than what we had experienced with Gary. For example, we did our best never to isolate ourselves behind intimidatingly closed office doors to read or write, and we strove to be constantly available to our graduate students, whenever they needed it. Yet, insensibly over time, even 
the most rebellious among us observed that, in the interest of greater efficiency in our work, it made sense for us to go back on some of our initial decisions, and our approach began to converge increasingly toward Gary's in many respects. Perhaps there is no better tribute to a teacher than when his former students attempt to emulate his example on a daily basis, in most everything that they do...

We hope that this text will be of help to all those around the world who are searching for ways to make a success of their research career. This may be particularly the case in science, but we feel that the lessons of Gary's method could apply equally well to any scholarly pursuit. Perhaps even simply reading our

\section{REFERENCES}

Anderson, D. M., and Sposito, G. (1963). Rate of adsorption of water vapour by degassed Arizona bentonite. Nature 199, 1085-1086. doi: 10.1038/1991 $085 \mathrm{a} 0$

Anderson, D. M., Sposito, G., and Leaming, G. F. (1963). Volume changes of a thixotropic, sodium bentonite suspension during sol-gel-sol transition. Science 141, 1040-1041. doi: 10.1126/science.141.3585.1040

Babcock, K. L. (1963). Theory of the chemical properties of soil colloidal systems at equilibrium. Hilgardia 34, 417-542. doi: 10.3733/hilg.v34n11p417

Bourg, I. C., Sposito, G., and Bourg, A. C. M. (2007). Modeling the acid-base surface chemistry of montmorillonite. J. Colloid Interface Sci. 312, 297-310. doi: 10.1016/j.jcis.2007.03.062

Chang, F. R. C., Skipper, N. T., and Sposito, G. (1997). Monte Carlo and molecular dynamics simulations of interfacial structure in lithium-montmorillonite hydrates. Langmuir 13, 2074-2082. doi: 10.1021/la9603176

Chorover, J., Kraemer, S. M., Cervini-Silva, J., and Maurice, P. (2007). Physical chemistry of soils and aquifers: a special issue in honor of Garrison Sposito. Geochim. Cosmochim. Acta 71, 5579-5582. doi: 10.1016/j.gca.2007. 09.010

Duckworth, O. W., Bargar, J. R., and Sposito, G. (2009). Coupled biogeochemical cycling of iron and manganese as mediated by microbial siderophores. Biometals 22, 605-613. doi: 10.1007/s10534-009-9220-9

Gelman, A. (2014). Hurricanes vs. Himmicanes. The Washington Post, June 5. Available online at: https://www.washingtonpost.com/news/monkey-cage/wp/ 2014/06/05/hurricanes-vs-himmicanes/ (Accessed October 14, 2016).

Maurice, P., Forsythe, J., Hersman, L., and Sposito, G. (1996). Application of atomic-force microscopy to studies of microbial interactions with hydrous Fe(III)-oxides. Chem. Geol. 132, 33-43. doi: 10.1016/S0009-2541(96)0 0039-3

Newton, A. G., and Sposito, G. (2015). Molecular dynamics simulations of pyrophylite edge surfaces: structure, surface energies, and solvent accessibility. Clays Clay Miner. 63, 277-289. doi: 10.1346/CCMN.2015. 0630403

Nuijten, M. B., Hartgerink, C. H. J., van Assen, M. A. L. M., Epskamp, S., and Wicherts, J. M. (2015). The prevalence of statistical reporting errors in psychology (1985-2013). Behav. Res. Methods. doi: 10.3758/s13428-015-0664-2. [Epub ahead of print].

Peña, J., Bargar, J. R., and Sposito, G. (2011). Role of bacterial biomass in the sorption of $\mathrm{Ni}$ by biomass-birnessite assemblages. Environ. Sci. Technol. 45, 7338-7344. doi: 10.1021/es201446r

Perrier, E., Rieu, M., Sposito, G., and de Marsily, G. (1996). Models of the water retention curve for soils with a fractal pore size distribution. Water Resour. Res. 32, 3025-3031. doi: 10.1029/96WR01779

Rieu, M., and Sposito, G. (1991a). The water characteristic curve of fragmented porous media and the fractal nature of soil structure. Comptes Rendus de l'Académie des Sciences Serie II 312, 1483-1489.

Rieu, M., and Sposito, G. (1991b). Fractal fragmentation, soil porosity, and soil-water properties.1. Theory. Soil Sci. Soc. Am. J. 55, 1231-1238. doi: $10.2136 /$ sssaj1991.03615995005500050006x description of the various components above may already cause a number of readers to reflect on their own practice, question some aspects of it, and hopefully get ideas on how to improve things. We would feel rewarded, and we would view it as an added tribute to Gary, if this could happen even to a small extent.

\section{AUTHOR CONTRIBUTIONS}

All the authors have contributed equally to the discussions leading to this article. LC and PB have coordinated the redaction of the text.

Rieu, M., and Sposito, G. (1991c). Fractal fragmentation, soil porosity, and soilwater properties.1. Applications. Soil Sci. Soc. Am. J. 55, 1239-1244. doi: 10.2136/sssaj1991.03615995005500050007x

Sánchez-García, M., Roig, A., Sánchez-Monedero, M. A., and Cayuela, M. L. (2014). Biochar increases soil $\mathrm{N}_{2} \mathrm{O}$ emissions produced by nitrificationmediated pathways. Front. Environ. Sci. 2:25. doi: 10.3389/fenvs.2014. 00025

Sijtsma, K., Veldkamp, C. L., and Wicherts, J. M. (2016). Improving the conduct and reporting of statistical analysis in psychology. Psychrometrika 81, 33-38. doi: 10.1007/s11336-015-9444-2

Spiro, T. G., Bargar, J. R., Sposito, G., and Tebo, B. M. (2010). Bacteriogenic manganese oxides. Acc. Chem. Res. 43, 2-9. doi: 10.1021/ar800232a

Sposito, G. (1969). Does a generalized Heisenberg principle operate in social sciences? Inq. Interdisciplinary J. Philos. 12, 356-360. doi: $10.1080 / 00201746908601571$

Sposito, G. (1981). The operational definition of the zero point of charge in soils. Soil Sci. Soc. Am. J. 45, 292-297. doi: 10.2136/sssaj1981.0361599500 $4500020013 \mathrm{x}$

Sposito, G. (1986). The physics of soil water physics. Water Resour. Res. 22, S83-S88. doi: 10.1029/WR022i09Sp0083S

Sposito, G. (1992). "Promoting science and engineering careers in academe," in Science and Engineering Programs: On Target for Women?, eds M. L. Matyas and L. S. Dix (Washington, DC: National Academy Press), 101-118.

Sposito, G. (1993). "Solute lifetime correlations in chemical transport through field soils," in Water Flow and Solute Transport in Soils: Developments and Applications In Memoriam Eshel Bresler (1930-1991), eds D. Russo and G. Dagan (Berlin: Springer-Verlag), 82-95. doi: 10.1007/978-3-642-77947-3_7

Sposito, G. (1994). Chemical Equilibria and Kinetics in Soils. New York, NY: Oxford University Press.

Sposito, G. (1997). Ergodicity and the 'scale effect'. Adv. Water Resour. 20, 309-316. doi: 10.1016/S0309-1708(96)00054-1

Sposito, G. (2001). Topological groundwater hydrodynamics. Adv. Water Resour 24, 793-801. doi: 10.1016/S0309-1708(00)00077-4

Sposito, G., Holtzclaw, K. M., Charlet, L., Jouany, C., and Page, A. L. (1983) Sodium calcium and sodium magnesium exchange on Wyoming bentonite in perchlorate and chloride background ionic media. Soil Sci. Soc. Am. J. 47, 51-56. doi: 10.2136/sssaj1983.03615995004700010010x

Sposito, G., and Prost, R. (1982). Structure of water adsorbed on smectites. Chem. Rev. 82, 553-573. doi: 10.1021/cr00052a001

Sposito, G., Skipper, N. T., Sutton, R., Park, S. H., Soper, A. K., and Greathouse, J. A. (1999). Surface geochemistry of the clay minerals. Proc. Natl. Acad. Sci. U.S.A. 96, 3358-3364. doi: 10.1073/pnas.96.7.3358

Sposito, G., and Zabel, A. (2003). The assessment of soil quality. Geoderma 114, 143-144. doi: 10.1016/S0016-7061(03)00038-7

Sutton, R., and Sposito, G. (2005). Molecular structure in soil humic substances: the new view. Environ. Sci. Technol. 39, 9009-9015. doi: 10.1021/es05 $0778 \mathrm{q}$

Sutton, R., and Sposito, G. (2006). Molecular simulation of humic substance-Camontmorillonite complexes. Geochim. Cosmochim. Acta 70, 3566-3581. doi: 10.1016/j.gca.2006.04.032 
Thomas, G. W. (1992). In defense of observations and measurements. Soil Sci. Soc. Am. J. 56:1979. doi: 10.2136/sssaj1992.036159950056000 $60054 \mathrm{x}$

Toner, B., and Sposito, G. (2005). Reductive dissolution of biogenic manganese oxides in the presence of a hydrated biofilm. Geomicrobiol. J. 22, 171-180. doi: 10.1080/01490450590946004

Vatn, A., and Bromley, D. W. (1994) Choices without prices without apologies. J. Envir. Econ. Manag. 26, 129-148. doi: 10.1006/jeem.1994.1008

Weissgerber, T. L., Garovic, V. D., Winham, S. J., Milic, N. M., and Prager, E. M. (2016). Transparent reporting for reproducible science. J. Neurosci. Res. 94, 859-864. doi: 10.1002/jnr.23785
Conflict of Interest Statement: The authors declare that the research was conducted in the absence of any commercial or financial relationships that could be construed as a potential conflict of interest.

Copyright (c) 2016 Charlet, Baham, Giraldez, Lo, Aristilde and Baveye. This is an open-access article distributed under the terms of the Creative Commons Attribution License (CC BY). The use, distribution or reproduction in other forums is permitted, provided the original author(s) or licensor are credited and that the original publication in this journal is cited, in accordance with accepted academic practice. No use, distribution or reproduction is permitted which does not comply with these terms. 